Nicole Rupschus

\title{
Frauen in Qumran
}

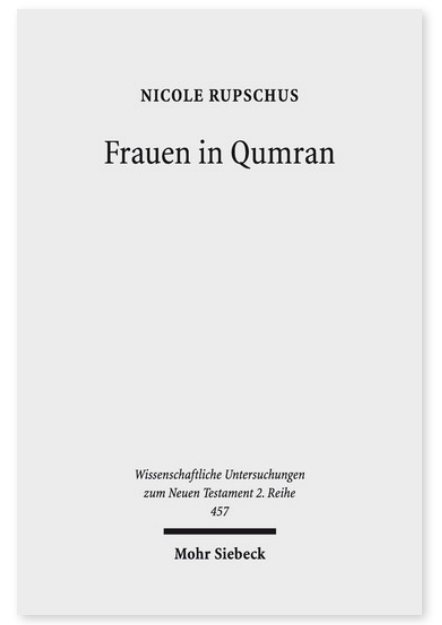

2017. XII, 335 Seiten. WUNT II 457

ISBN 978-3-16-155782-8

DOI 10.1628/978-3-16-155782-8

eBook PDF 99,00€

ISBN 978-3-16-155647-0

fadengeheftete Broschur 99,00€
Nicole Rupschus berührt in ihrer Studie klassische und aktuelle Themen der Qumranforschung, die sich in der Frage nach den Einwohnern Qumrans, der Intention der Qumrantexte und dem Quellenwert der Essenerberichte bündeln lassen. Konkret erfasst sie drei wichtige Aspekte: Erstens die Archäologie, zweitens die gruppenspezifischen Texte der Höhlen in und bei Qumran und drittens die antiken Berichte über die Essener. Eine separate Betrachtung von Archäologie und Texten ist hierbei grundlegend.

Die Autorin bezieht Stellung zu den auf dem Friedhof gefundenen Frauen- und Kinderskeletten. Ein weiterer Schwerpunkt liegt auf den Damaskus- und Serekh-Texten sowie der Gemeinschaftsregel, ihren Verbindungslinien und

Gemeinschaftszuschreibungen. Zuletzt analysiert sie den Aussagegehalt der antiken Essenertexte. In der Zusammenschau ergeben sich neue Facetten für Frauen und Frauenbilder in Bezug auf Qumran.

Nicole Rupschus Geboren 1984; 2005-12 Studium der Ev. Theologie an der Universität Greifswald; 2013-17 Promotionsstudium an den Universitäten in Greifswald und Zürich; 2014-17 Projektmitarbeiterin im Rahmen eines SNFForschungsprojektes bei Prof. Dr. Jörg Frey an der Universität Zürich; 2017 Promotion; derzeit Editor im Verlag Walter de Gruyter.

\section{Jetzt bestellen:}

https://mohrsiebeck.com/buch/frauen-in-qumran-9783161557828?no_cache=1

order@mohrsiebeck.com

Telefon: +49 (0)7071-923-17

Telefax: +49 (0)7071-51104 